\title{
Interaction of bleomycin with DNA
}

\author{
James C. Quada, Jr., Guy F. Zuber and Sidney M. Hecht \\ Departments of Chemistry and Biology, University of Virginia, Charlottesville, Virginia 22901 USA
}

\begin{abstract}
It has been shown previously that two structural domains of bleomycin mediate the interaction of the antitumor antibiotic with DNA. At least three lines of evidence indicate that the metal binding domain is the predominant partner, and is responsible for the sequence selectivity of DNA cleavage observed for $\mathrm{Fe}(\mathrm{II}) \cdot \mathrm{BLM}$. The bithiazole $+\mathrm{C}$-terminus has been shown previously to bind to DNA, but not to exhibit any sequence selectivity. Presently, it is shown that the bithiazole $+\mathrm{C}$ terminus may also exhibit sequence selectivity, albeit not in the same fashion as bleomycin itself. The potential of this selectivity to contribute to the recognition of high affinity sites on DNA by bleomycin is discussed.
\end{abstract}

\section{INTRODUCTION}

The bleomycins (BLMs) are a family of glycopeptide-derived antitumor antibiotics believed to exert their therapeutic effects through the degradation of DNA (refs. 1,2) and possibly RNA (ref. 3). The clinically used mixture of bleomycins, called Blenoxane, consists of a number of congeners that differ at the C-terminus; bleomycin $\mathrm{A}_{2}$ (Fig. 1) is the major constituent of this mixture. Under physiological conditions, polynucleotide degradation by bleomycin requires dioxygen and an appropriate metal ion as cofactors (refs. 2, 4); $\mathrm{Fe}^{2+}$ can certainly support this process (ref, 5) and $\mathrm{Cu}^{+}$may also suffice (ref. 6). The products of DNA degradation by $\mathrm{Fe}$ (II)•BLM have been characterized (ref. 2, 4) and those resulting from RNA degradation have been studied as well (ref. 3).

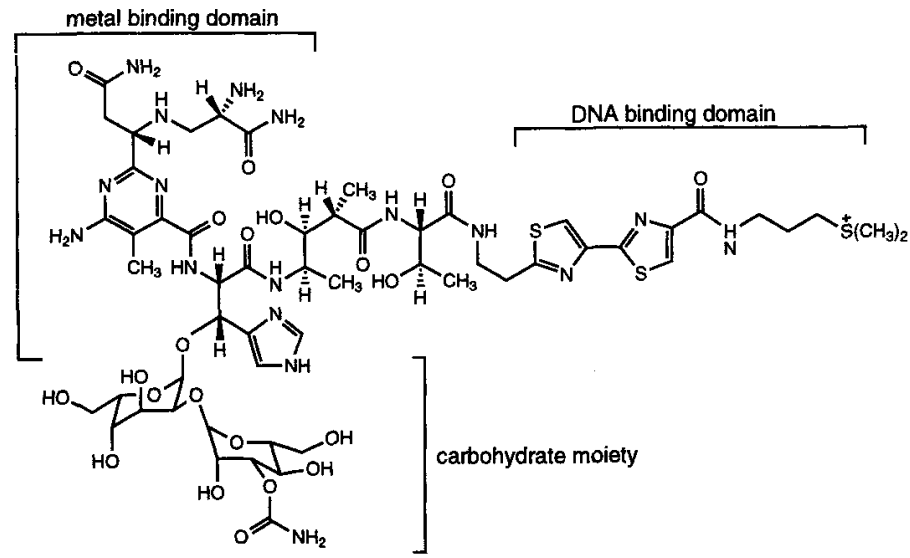

Fig. 1 Structural formula of bleomycin $\mathrm{A}_{2}$. The individual domains are indicated.

\section{SEQUENCE SELECTIVE CLEAVAGE OF DNA}

One of the most remarkable facets of DNA cleavage by metallobleomycins is the observed sequence selectivity. Most of the observed sites of oxidative cleavage involve the pyrimidine nucleotides in 5'-GC-3' and 5'-GT-3' sequences; a subset of these are cleaved with particularly high efficiency (refs. 2, 4). The molecular basis for the choice of 5'-Gpyr-3' sequences as preferred cleavage sites is poorly understood, although it may be related to the fact that the minor groove of DNA is relatively wide and shallow at such sites. Consistent with this conjecture were the findings that bleomycin cleaved DNA and RNA preferentially at bulges (refs. 3, 7); BLM also exhibited enhanced RNA cleavage at the junction of single- and double stranded structures (ref. 3) and enhanced DNA cleavage at the junction between a duplex and triplex structure (ref. 8). All of these structures are believed to have relatively wide minor grooves relative to canonical B-form DNA. 
In contrast to the dearth of information concerning the molecular basis for the choice of DNA sequences cleaved preferentially by bleomycin, the structural elements in bleomycin responsible for sequence selective modification of DNA are better understood. For example, the self-complementary dodecanucleotide $\mathrm{CGCT}_{3} \mathrm{~A}_{3} \mathrm{GCG}$ was cleaved at both cytidine 3 and cytidine 11 , although the latter was strongly preferred by $\mathrm{Fe}(\mathrm{II}) \cdot \mathrm{BLM} \mathrm{A}_{2}$. Alteration of the C-substituent had no effect on the ratio of cleavage at these two sites, but alteration of the metal binding domain had profound effects (ref. 9), consistent with the thesis that the metal binding domain controls the preferred sites of cleavage. Mascharak and coworkers (ref. 10) have also shown that a model of the binding domain of bleomycin had essentially the same selectivity of DNA cleavage as bleomycin itself. Finally, Carter et al. (ref. 11) studied a series of synthetic BLM analogues in which the bithiazole and metal binding domains were separated by peptide linkers of varying lengths. That all of these species cleaved DNA with the same sequence selectivity argues that the metal binding domain is the primary mediator of sequence selective binding by bleomycin.

\section{A POSSIBLE ROLE FOR THE BITHIAZOLE IN SEQUENCE SELECTIVE DNA BINDING}

While the foregoing experiments argue convincingly that the metal binding domain is the primary mediator of sequence selectivity exhibited by BLM, they do not preclude a role for the bithiazole moiety. In fact, there is unequivocal evidence for DNA binding by the bithiazole + C-terminus of bleomycin (refs. 12-15); it is only the possible sequence selectivity of that binding which is uncertain.

Functionalized bithiazoles have been utilized in an effort to determine whether the bithiazole moiety has any intrinsic sequence selectivity. Bithiazole 1, containing an attached EDTA group, effected DNA strand scission in

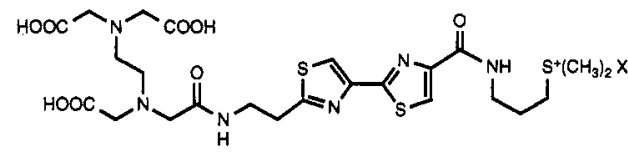

1

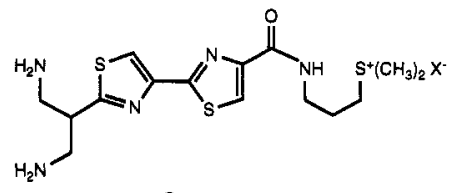

2

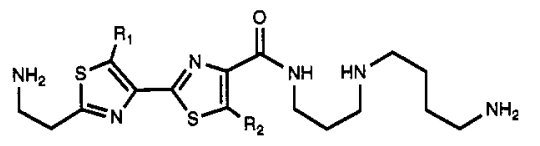

$3 R_{1}, R_{2}=H$

$4 R_{1}=C_{1}, R_{2}=H$

$5 \quad R_{1}=\mathrm{H}, \mathrm{R}_{2}=\mathrm{Cl}$

$6 R_{1}, R_{2}=C l$

$7 \quad R_{1}=B r, R_{2}=H$

the presence of $\mathrm{Fe}^{2+}+\mathrm{H}_{2} \mathrm{O}_{2}$, but no sequence selectivity could be discerned (ref. 16). In the belief that this may have been due to the diffusible nature of the reactive species, another type of bithiazole (2) was prepared. Upon admixture of $\mathrm{Co}^{2+}$, bithiazole 2 effected $\mathrm{O}_{2}$ dependent DNA modification. Analysis of the sites modified indicated that every guanosine residue had undergone oxidation, arguing that the bithiazole was capable of binding to many sites but could only modify guanine nucleotides (ref. 17).

In an effort to prepare bithiazole derivatives having highly reactive functionalities that could be used to probe a bound DNA substrate in a spatially defined fashion, we prepared a number of halogenated bithiazoles.

\section{DNA CLEAVAGE BY CHLORINATED BITHIAZOLES}

Initially, three chlorinated bithiazoles (4-6) structurally related to bleomycin $\mathrm{A}_{5}$ were prepared. The first DNA cleavage experiments employed supercoiled plasmid pBR322 DNA, which underwent relaxation when irradiated in the presence of bithiazole 5 or 6 (Fig. 2). As shown in the figure, cleavage proceeded more efficiently in the presence of bithiazole 6 which has two chloro groups and was completely dependent on light (data not shown). 
The involvement of the chloro groups in the cleavage was underscored by the lack of cleavage obtained when nonchlorinated bithiazole 3 was employed under the same conditions (not shown) (ref. 18). It was also shown that $\mathrm{O}_{2}$ was not required for DNA cleavage. It may be noted that bithiazole 6 produced detectable relaxation of plasmid DNA when employed at $2 \mathrm{nM}$ concentration. Since the plasmid was present only at 3-4 nM

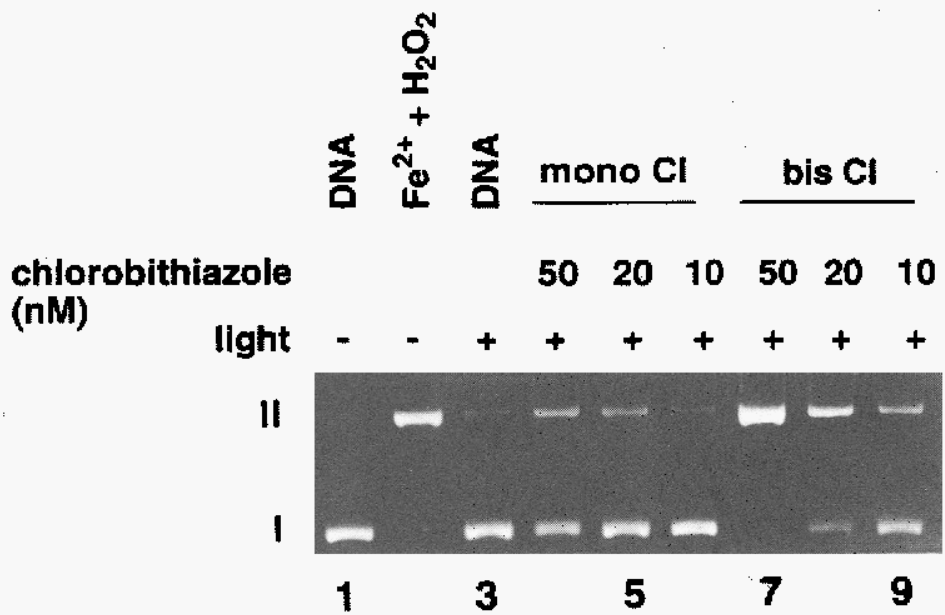

Fig. 2 Cleavage of supercoiled DNA by bithiazoles 5 (lanes 4-6) and 6 (lanes 7-9) after 30 min of irradiation with $254 \mathrm{~nm}$ light through a Pyrex filter. Lanes 1 and 3, DNA alone; lane 2, $10 \mu \mathrm{M} \mathrm{Fe} \mathrm{e}^{2+}+0.19 \% \mathrm{H}_{2} \mathrm{O}_{2}$.

concentration, the reaction was extraordinarily efficient. The chlorinated bithiazoles structurally related to bleomycin $\mathrm{A}_{2}$ were also investigated and found to effect plasmid relaxation with efficiencies comparable to bithiazoles 4-6.

The foregoing observations, as well as published reports of the behavior of other halogenated heterocycles as light activated DNA cleaving agents (refs. 19-22), suggest strongly that DNA cleavage by the chlorobithiazoles involves initial light-mediated C-Cl bond homolysis. Because either chlorine or aryl radicals could in principle afford the observed products, DNA relaxation was studied further using chlorobithiazole 4 in direct comparison with the analogous bromobithiazole derivative (7). As shown in Fig. 3, the chlorobithiazole was much more potent than the analogous bromobithiazole, suggesting strongly that $\mathrm{Cl} \cdot$ is the species that mediates DNA damage.

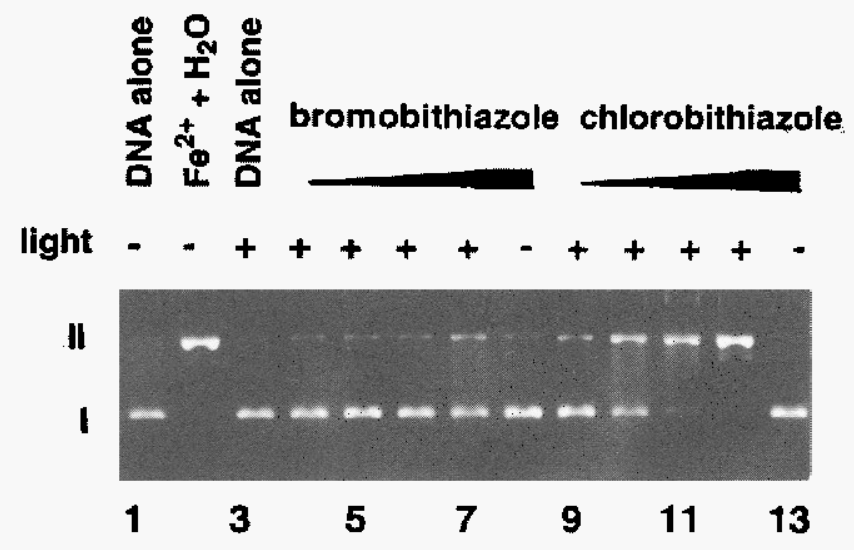

Fig. 3 Cleavage of supercoiled plasmid pBR322 DNA by halobithiazoles 7 (lanes 4-7) and 4 (lanes 9-12) at 20, 50,100 and $200 \mathrm{nM}$ concentrations over a period of $15 \mathrm{~min}$. Lanes 1 and 3, DNA alone; lane $2,10 \mu \mathrm{M} \mathrm{Fe}^{2+}+$ $0.19 \% \mathrm{H}_{2} \mathrm{O}_{2}$; lanes 8 and $13,200 \mu \mathrm{M}$ bithiazoles 7 and 4 , respectively. 
The ability of the chlorinated bithiazoles to effect DNA cleavage in a sequence dependent fashion was studied using a 158-base pair linear DNA duplex as a substrate (Fig. 4). As shown in the figure, when $3^{\prime}-$ and $5{ }^{\prime}-32 \mathrm{p}$ end labeled DNAs were treated with $1 \mu \mathrm{M}$ bithiazole 5 a number of discrete cleavage bands were observed (lanes 4 and 5). Thus this chlorinated bithiazole was found to be capable of mediating sequence selective cleavage of a DNA substrate. The same property was also noted for bithiazoles $\mathbf{4}$ and $\mathbf{6}$, as well as the respective chlorinated bithiazoles structurally related to bleomycin $\mathrm{A}_{2}$ (data not shown). Critically, the sites of cleavage were not related in any systematic fashion to the sites of BLM-mediated cleavage of the same DNA (cf lanes 4 and 6;5 and 7).

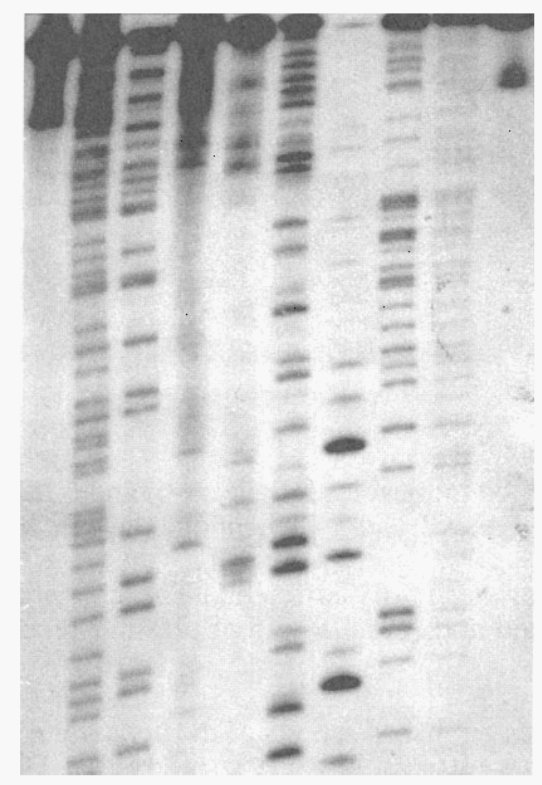

Fig. 4 Cleavage of a $32 \mathrm{P}$-end labeled DNA duplex by bithiazole 5 . The 158-base pair duplex was labeled either at the 5' (lanes 1-4,6) or 3'-end (lanes 5, 7-10) and treated with $1 \mu \mathrm{M}$ bithiazole 5 (lanes 4 and 5) during a 10-min period in which the sample was irradiated with a 100 watt low pressure mercury lamp. Lanes 1 and 10 , DNA alone; lanes 2 and 8, G-lane; lanes 3 and 9, G + A lane; lanes 6 and 7, 2 mM Fe(II)-BLM A2.

In order to gain some insight into the sequence selectivity of DNA cleavage by the chlorobithiazoles, we employed as substrate a self-complementary octanucleotide whose interaction with $\mathrm{Fe}(\mathrm{II}) \cdot \mathrm{BLM}$ has been characterized biochemically (refs. 2, 4, 23) and by NMR spectroscopy (refs. 24, 25). Treatment of 5'-CGCTAGCG-3' with chlorbithiazole 4 afforded a single major cleavage band at thymidine 4 , while treatment with chlorobithiazole 5 gave a lesion at adenosine 5 . Interestingly, bis-chlorobithiazole 6 gave bands corresponding to both $\mathrm{T}_{4}$ and $\mathrm{A}_{5}$, suggesting that all three species bound to the DNA octanucleotide substrate in the same fashion (Fig. 5).

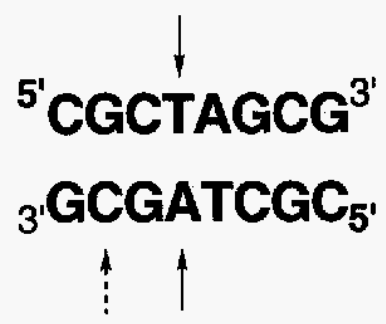

Fig. 5 Sites of DNA cleavage mediated by chlorobithiazoles 4-6 (solid arrows) and by Fe(II) $\cdot$ BLM (dashed arrow).

As described previously (refs. 2, 4, 23), $\mathrm{Fe}$ (II)•BLM mediates degradation of 5'-CGCTAGCG-3' predominantly at $\mathrm{C}_{3}$ and $\mathrm{C}_{7}$ and constitutes a particularly high efficiency substrate for cleavage by $\mathrm{Fe}(\mathrm{II}) \cdot \mathrm{BLM}$. Recent ${ }^{1} \mathrm{H}$ NMR studies of the interaction of $\mathrm{Zn}(\mathrm{II}) \cdot \mathrm{BLM} \mathrm{A}_{2}$ and $\mathrm{Zn}(\mathrm{II}) \bullet \mathrm{BLM} \mathrm{A}_{5}$ (refs. 24,25 ) and well as $\mathrm{Zn}(\mathrm{II}) \cdot$ deglycoBLM $\mathrm{A}_{2}$ 
(ref. 26) with this octanucleotide have verified that the metal binding domain of these species are in close proximity to the deoxyribose moieties of the affected nucleotides. Interestingly, these NMR studies have also shown that the bithiazoles are in close proximity to $\mathrm{T}_{4}$ and $\mathrm{A}_{5}$ in all of the complexes studied. It is intriguing that the sites modified by the chlorinated bithiazoles are the same as those with which $\mathrm{Zn}$ (II)・BLM and $\mathrm{Zn}$ (II) •deglycoBLM normally interact in a highly efficient DNA substrate for BLM. It seems possible that the subset of 5'-GT-3' and 5'-GC-3' sequences in DNA that are cleaved with the greatest efficiency by BLM are those containing flanking sequences that are intrinsically good substrates for binding by the bithiazole moiety of bleomycin.

\section{ACKNOWLEDGMENTS}

This work was supported by Research Grant CA53913 from the National Cancer Institute.

\section{REFERENCES}

1. B. I. Sikic, M. Rozencweig and S. K. Carter, eds. Bleomycin Chemotherapy, Academic Press, Orlando (1985).

2. A. Natrajan and S. M. Hecht. In Molecular Aspects of Anticancer Drug-DNA Interactions (S. Neidle and M. J. Waring, eds.), Vol. 2, pp. 197-242. Macmillan Press, London (1993).

3. S. M. Hecht. Bioconjugate Chem. 5, 513 (1994).

4. S. A. Kane and S. M. Hecht. Prog. Nucleic Acid Res. Mol. Biol. 49, 313 (1994).

5. E. A. Sausville, J. Peisach and S. B. Horwitz. Biochemistry 17, 2740 (1978).

6. G. M. Ehrenfeld, J. B. Shipley, D. C. Heimbrook, H. Sugiyama, E. C. Long, J. H. van Boom, G. A. van der Marel, N. J. Oppenheimer and S. M. Hecht. Biochemistry 26, 931 (1987).

7. L. D. Williams and I. H. Goldberg. Biochemistry 27, 3004 (1988).

8. S. A. Kane, S. M. Hecht, J.-S. Sun, T. Garestier and C. Hélène. Biochemistry 34, 16715 (1995).

9. H. Sugiyama, R. E. Kilkuskie, L.-H. Chang, L.-T. Ma, S. M. Hecht, G. A. van der Marel and J. H. van Boom. J. Am. Chem. Soc. 108, 3852 (1986).

10. R. J. Guajardo, S. E. Hudson, S. J. Brown and P. K. Mascharak. J. Am. Chem. Soc. 115, 7971 (1993).

11. B. J. Carter, V. S. Murty, K. S. Reddy, S.-N. Wang and S. M. Hecht. J. Biol. Chem. 265, 4193 (1990).

12. T. T. Sakai, J. M. Riordan and J. D. Glickson. Biochemistry 21, 805 (1982).

13. M. Chien, A. P. Grollman and S. B. Horwitz. Biochemistry 21, 3711 (1982).

14. J. Kross, W. D. Henner, S. M. Hecht and W. A. Haseltine. Biochemistry 214310 (1982).

15. J.-P. Hénichart, J.-L. Bernier, N. Helbecque and R. Houssin. Nucleic Acids Res. 13, 6703 (1985).

16. S. A. Kane, A. Natrajan and S. M. Hecht. J. Biol. Chem. 269, 10899 (1994).

17. S. A. Kane, H. Sasaki and S. M. Hecht. J. Am. Chem. Soc. 117, 9107 (1995).

18. J. C. Quada, Jr., M. J. Levy and S, M. Hecht. J. Am. Chem. Soc. 115, 12171 (1993).

19. J. Decuyper, J. Piette, M. Lopez, M.-P. Merville and A. van de Vorst. Biochem. Pharmacol. 33, 4025 (1984).

20. A. G. Motten, G. R. Buettner and C. F. Chignell. Photochem. Photobiol. 42, 9 (1985).

21. T. A. Ciulla, G. A. Epling and I. E. Kochevar. Photochem. Photobiol. 43, 607 (1986).

22. T. Matsumoto, Y. Utsumi, Y. Sakai, K. Toyooka and M. Shibuya. Heterocycles 34, 1697 (1992).

23. R. B. Van Atta, E. C. Long, S. M. Hecht, G. A. van der Marel and J. H. van Boom. J. Am. Chem. Soc. 111, 2722 (1989).

24. R. A. Manderville, J. F. Ellena and S. M. Hecht. J. Am. Chem. Soc. 116, 10851 (1994).

25. R. A. Manderville, J. F. Ellena and S. M. Hecht. J. Am. Chem. Soc. 117, 7891 (1995).

26. S. J. Sucheck and S. M. Hecht, unpublished results. 